В заключение И.А. Груздев обратился к интернет-аудитории с предложением выбрать лучшие доклады из числа прозвучавших, а также высказать свои пожелания по дальнейшему развитию конференции «Электронный век культуры» .

Все мероприятия сопровождались онлайнтрансляцией в Интернете на главной странице сайта Российской ассоциации электронных библиотек www.aselibrary.ru. За ходом выступлений участников ежедневно дистанционно наблюдали более тысячи человек.

Основная информация об ЭВК представлена на сайте http://www.elvek.ru, включая информационный отчет (http://www.elvek.ru/conference/ infootchet/), видео- (http://www.elvek.ru/ conference/videootchet/) и фотоотчет (http:// www.elvek.ru/conference/fotootchet/).

Н.В. Авдеева, начальник управления функиионирования и лониторинга клиентского сервиса РГБ

А.А. Андрианова, главный специалист отдела поддержки доступа к электроннылм ресурсал РГБ

O.В. Никулина, начальник отдела поддержки доступак электронныл ресурсам РГБ

Фото Е.Г. Мальцевой

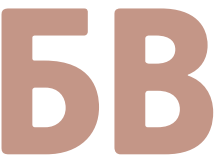

Проблемы информатизации
УДК [021:004]:005.745(100)

ББК 78.3с51л0(0)

\section{Конференция "LIBCOM-2012"}

12-16 ноября 2012 г. в ближнем Подмосковье (г. Химки) состоялась Шестнадцатая международная конференция и выставка «LIBCOM-2012»: «Информационные технологии, компьютерные системы и издательская продукция для библиотек» . Бессменный организатор конференции - Государственная публичная научно-техническая библиотека России позиционирует данную конференцию (которую, кстати, иногда называют «зимний Крым») как площадку для обсуждения самых острых вопросов, волнующих руководителей библиотек, практиков библиотечного дела, преподавателей вузов и других образовательных учреждений, сотрудников издательств, книготорговых организаций, деятелей науки, культуры и образования.

Конечно, формат журнальной статьи ставит жесткие ограничения по объему, поэтому сосредоточимся на самых острых обсуждениях и мероприятиях.

На пленарном заседании, где с приветственным словом и докладом на тему «Библиотеки и цифровая неизбежность: в ожидании всеобщего понимания» выступил генеральный директор ГПНТБ России Я.Л. Шрайберг, были обозначены основные моменты и изменения в жизни библиотек на современном этапе: смена носителей, снижение интереса к чтению, появление концептуально иных способов производства, получения и потребления информации. Вступительное слово было предоставлено заместителю министра культуры Российской Федерации Г.П. Ивлиеву, члену Совета Федера- 
ции Федерального Собрания Российской Федерации С.С. Журовой, генеральному директору РГБ А.И. Вислому, главе городского округа г. Химки О.Ф. Шахову.

Центральной дискуссионной площадкой на конференции стало ток-шоу «Библиотеки и книжный рынок в ожидании законодательных перемен: грядет ли взаимопонимание и сотрудничество или противостояние?». Его цель - обозначение проблем и предложение способов решения обеспечения взаимодействия библиотек, издателей, книгораспространителей и агрегаторов электронной информации в современном правовом поле в интересах авторов, пользователей и общества в целом. Итогом дискуссии стало принятие решения о проведении круглого стола с участниками ток-шоу (представителями библиотечного сообщества, издательского и книгораспространительного сообщества, агрегаторов, Федерального агентства по печати и массовым коммуникациям) в Совете Федерации Федерального Собрания Российской Федерации и о более подробном и детальном рассмотрении этой проблемы.

Очень интересным и новым стало проведение в рамках конференции общероссийского совещания по итогам выполнения первых двух этапов проекта «Разработка информационной системы доступа к электронным каталогам библиотек сферы образования и науки в рамках единого интернет-ресурса». Напомним, эта система будет обеспечивать развитие единого информационного пространства библиотек России путем предоставления доступа к электронным каталогам и полнотекстовым ресурсам библиотек сферы образования и науки Российской Федерации. В перспективе должна быть создана единая навигационная система доступа к печатным и электронным фондам библиотек системы образования и науки страны.

Следующий вопрос, который рассматривался на данном совещании, был посвящен проблемам выполнения проекта «Развитие и обеспечение работы интегрированного сводного каталога научно-технической информации как поливидового распределенного банка данных корпоративного пользования научно-технических документов, поступающих в организации-фондодержатели научно-технической информации России и стран СНГ». Задача проекта - повышение эффективности использования информационных ресурсов научных, технических и специальных библиотек России и стран СНГ, расширение круга пользователей, увеличение объемов электронных информационных ресурсов.

На первом заседании открытой сессии конференции рассматривались различные аспекты государственной библиотечной политики. В выступлении Е.В. Линдеман (ГПНТБ России) «Электронные ресурсы как часть гибридных ресурсов библиотек: проблемы пользователей и библиотекарей» анализировались правовые нормы обслуживания пользователей электронными ресурсами. Тему «Правовое регулирование библиотечно-информационных услуг» продолжила О.Ф. Бойкова (РГБ), подробнейшим образом охарактеризовав основные законодательные документы, регламентирующие деятельность библиотек на современном этапе.

В.Г. Дригайло (Национальный технический университет Украины «Киевский политехнический институт». Научно-техническая библиотека им. Г.И. Денисенко) обстоятельным докладом «Исследование динамики запросов от предприятий, организаций, учреждений в отдел газетных фондов НБУВ на получение необходимой газетной информации и их удовлетворение» проанализировал запросы от предприятий, организаций, учреждений в отдел газет за 1991-2010 годы.

О.Б. Ушакова (Красноярский центр научно-технической информации и библиотек Красноярской железной дороги) озадачила 
всех вопросом «Нужна ли библиотеке “лестница лояльности” или Как удержать читателя?» . Это выступление было посвящено важнейшим вопросам привлечения читателей, улучшения обслуживания, предоставления качественных информационных услуг.

На втором заседании открытой сессии «Современное образование, электронные учебники, библиотеки и электронные библиотечные системы в вузе: состояние и перспективы» с вступительным словом выступил Я.Л. Шрайберг. Докладчиками и участниками круглого стола были рассмотрены наиболее актуальные проблемы, связанные с подготовкой нового закона об образовании, а также вопросы профессиональной подготовки специалистов библиотечного дела в системе среднего специального и высшего образования.

По теме «Учебная литература и комплектование фондов библиотек в условиях новых ФГОС» были представлены презентации издательств, подписных агентств, образовательно-издательского центра «Академия».

Следующая тема второго заседания - «Электронные ресурсы для образования и науки. Электронные библиотечные системы в вузах: опыт использования и программа развития». Н.В. Авдеева и О.В. Никулина (РГБ) рассказали о системе «Антиплагиат. РГБ», позволяющей проводить проверку электронных документов на наличие заимствований по Электронной библиотеке диссертаций РГБ. Целью проекта является повышение качества российского образования и науки путем побуждения авторов к самостоятельному написанию работ.

В рамках конференции состоялось еще много обсуждений о возможных путях развития библиотек в современном информационном пространстве. Например, на круглом столе «Ценности библиотек в цифровой среде», ведущими и основными выступающими которого были В.К. Степанов (МГУКИ, Москва) и Е.Н. Гусева (РГБ), обсуждались вопросы об имидже библиотек в цифровом мире, что может привлечь в библиотеку реального и виртуального читателя, насколько важна для библиотеки «погоня за технологиями» и с чего именно надо начать изменения современной роли библиотек.

В установочных сообщениях «Ценности библиотек в цифровой среде» и «Библиотека в цифровой и аналоговой среде: поиски стратегии» ведущие представили свои соображения о влиянии объективных и субъективных факторов на работу библиотечных учреждений, о поиске стратегии «голубого океана» в библиотечном обслуживании. Предлагались некоторые модели уже имеющейся и весьма востребованной работы библиотек для пользователей (И.К. Меньшов, ЦБС «Солнцево», Москва).
Дискуссионные обсуждения стратегических проблем, попытки «нащупать» современную миссию библиотеки в непрерывно растущем мире информации и коммуникаций происходят не в первый раз. Не всегда участники могут предложить готовые решения, но то, что этим необходимо заниматься и делать это должны именно профессионалы, специалисты, а не только и не столько руководители разных рангов, становится общепризнанным.

Заявленные в программе круглого стола вопросы обсуждались и после его завершения кулуарно, но очень горячо. И - полагаем - обсуждение и поиск стратегических и концептуальных решений для библиотек, живущих в современной цифровой среде, будет продолжен, так как он необходим не только для разработки сценариев конкретных действий, но и для некоей «самоидентификации» профессионального сообщества.

Еще одна очень живая и эмоциональная дискуссионная группа «Библиотечная инноватика как практика управления» (ведущая - Е.Н. Гусева) собралась в последний день работы конференции. На Либкоме подобное мероприятие, отдельно посвященное инновациям в библиотеках и для библиотек, проходит третий год подряд. Аудитория 2012 г. составила более 60 человек, причем обсуждение больше напоминало сбор соратников и обмен мнениями людей, давно и плодотворно работающих над проблемами развития библиотек.

Установочный доклад «Методология оценки библиотечных инноваций», озвученный Е.Н. Гусевой, был посвящен одной из возможных методологий, определяющих принципы и критерии оценки эффективности внедрения инноваций в библиотечную деятельность. Автор указала, что на сегодняшний день о методологии и методике оценки инноваций в социокультурной сфере можно пока говорить на уровне подходов и предложений, так как несмотря на то, что показатели эффективности деятельности (KPI) достаточно хорошо разработаны и применяются во многих сферах бизнеса, показатели же эффективности для государственных и муниципальных учреждений сферы культуры только еще предстоит разработать или адаптировать, взяв их из других сфер деятельности.

В докладе обоснован подход, согласно которому оценка эффективности инновации в библиотеке или библиотечной инновации (а это, по мнению автора, разные понятия) осуществляется экспертно по определенной схеме, в которой проставляется результат значимости в баллах по нескольким критериям. При этом эксперт должен обладать всей полнотой информации об оцениваемой инновации (текст доклада опубликован в трудах конференции, см. http://www.gpntb. 
ru/libcom12/doc/006.pdf). Также было сделано сообщение о Всероссийском конкурсе библиотечных инноваций (организатор - РГБ), проводимом в период с октября 2012 г. по апрель 2013 г., который станет одним из вариантов апробации этой методологии, а главное, инструментом выявления инноваций в библиотечной сфере страны для их дальнейшего развития.

Заявленный доклад-сообщение и сама тема, естественно, вызвали дискуссию. Участники весьма оживленно встретили сообщение о «Фестивале информационных технологий» (И.К. Меньшов, ЦБС «Солнцево», Москва), сильную эмоциональную реакцию аудитории вызвало рассуждение «кто первый в инновации? И можно ли считать инновацией в одной библиотеке то, что другие библиотеки проделывали 15 лет назад?» (Е.В. Линдеман, ГПНТБ России, Москва). Участники задумывались над проблемой, кто и как будет «выполнять» заявленные в программе «Информационное общество» «инновации» по оцифровке $50 \%$ библиотечных фондов и $100 \%$ каталогов (А.И. Попов, ЦУНБ им. Н.А. Некрасова, Москва). Некоторые выступающие совершенно обоснованно говорили, что им безразлично, инновация это или нет - они просто это делают (М.В. Ивашина, Свердловская ОДЮБ, Екатеринбург) и что инновации настолько разнообразны и разноразмерны, что очень сложно определить их, но этим надо заниматься (Т.Д. Жукова, РШБА, Москва) и обучать этому других (Ю.В. Соколова, МУБиНТ, Ярославль). Участники искали «виноватых» в инновациях - говорили об «агентах изменений» и ответственности руководителя (О.Б. Ушакова, ЦНТИБ Красноярского филиала РЖКД, Красноярск, и Н.В. Абросимова, ЯОУНБ им. Н.А. Некрасова, Ярославль), рассуждали о требованиях общества к библиотекам и библиотекарям и о том, какие платные услуги, сверх традиционных бесплатных, может предложить библиотечная система отдаленного московского района (И.К. Меньшов, ЦБС «Солнцево», Москва).

Времени, как всегда, оказалось мало, но резюмируя прошедшее мероприятие, можно сказать, что говорить об инновациях, их формах, юридическом обеспечении и обосновании, о рисковой составляющей инновационного процесса, о новых требованиях к деятельности библиотек необходимо. И этот разговор касается всех.

В рамках конференции проходила выставка «Информационные технологии, компьютерные системы и издательская продукция для библиотек» .

Участники отметили высокий уровень организации всех мероприятий конференции и их практическую полезность. Подобные встречи специалистов способствуют повышению профессионального уровня, укрепляют и налаживают связи между библиотеками.

\author{
Е.Н. Гусева, \\ начальник Управления систелой фондов \\ Российской государственной библиотеки, \\ кандидат педагогических наук
}

Е.Ю. Рыбакова, заведующая сектором отдела хранения основных фондов Российской государственной библиотеки 